\title{
Edukasi Media Tote Bag Merubah Pengetahuan Serta Sikap Kader Posbindu Dalam Pengukuran Antropometri Dan Gizi Seimbang Lansia
}

\author{
Sarah Ameilia Subagyo ${ }^{1}$, Laras Sitoayu* ${ }^{1}$, Idrus Jus'at ${ }^{1}$, Nazhif Gifari ${ }^{1}$, Harna ${ }^{1}$ \\ ${ }^{1}$ Jurusan Gizi, Fakultas Ilmu-ilmu Kesehatan, Universitas Esa Unggul, Jakarta, Indonesia \\ Email Correspondence : laras@esaunggul.ac.id
}

\begin{abstract}
Abstrak
Kader posyandu lansia (Posbindu) mempunyai peranan penting dalam kegiatan Posbindu. Beberapa tugas kader adalah mengukur tinggi dan berat badan lanjut usia (lansia) juga memberikan edukasi mengenai gizi seimbang untuk lanjut usia (lansia), akan tetapi kader belum melakukan pengukuran tinggi badan serta berat badan dengan tepat. Tujuan penelitian ini untuk mengetahui apakah pemberian media tote bag dapat mempengaruhi perubahan pengetahuan serta sikap kader posbindu dalam pengukuran antropometri dan gizi seimbang pada lansia. Desain penelitian memakai metode Quasi Eksperiment dengan desain one group pre-test dan post-test pada 35 responden kader Posbindu di wilayah Pondok Kacang Timur, Pondok Aren, Tangerang Selatan. Mengukur perubahan pengetahuan serta sikap menggunakan kuesioner pre-post test. Uji analisis bivariat yang di gunakan adalah Uji Paired Sample T-test untuk data yang berdistribusi normal dan Uji Wilcoxon untuk data yang berdistribusi tidak normal. Hasil penelitian menunjukkan bahwa ada perubahan rata-rata nilai pengetahuan dan sikap kader Posbindu dalam pengukuran antropometri dan gizi seimbang pada lansia dibandingkan sebelum dan sesudah intervensi. Pemberian edukasi dengan media tote bag dapat merubah pengetahuan serta sikap kader Posbindu dalam pengukuran antropometri dan gizi seimbang pada lansia.
\end{abstract}

Kata Kunci: Antropometri, Gizi Seimbang Lansia, Kader Posbindu

How to Cite:

Subagyo, S., Sitoayu, L., Jus'at, I., Gifari, N., \& Harna, H. (2021). Edukasi Media Tote Bag Merubah Pengetahuan Serta Sikap Kader Posbindu Dalam Pengukuran Antropometri Dan Gizi Seimbang Lansia. Ghidza: Jurnal Gizi Dan Kesehatan, 5(1), 87 - 94. https://doi.org/10.22487/ghidza.v5i1.229

Published by:

Tadulako University

Address:

Soekarno Hatta KM 9. Kota Palu, Sulawesi Tengah,

Indonesia.

Phone: +628525357076

Email:ghidzajurnal@gmail.com
Article history :

Received : 22032021

Received in revised form : 08062021

Accepted : 11062021

Available online 09072021 


\begin{abstract}
Elderly posyandu cadres (Posbindu) have an important role in Posbindu activities. Some of cadres' tasks are measuring the height and weight of the elderly as well providing education on balanced nutrition for the elderly, but cadres have not carried out measurrements of height and weight accurately. The purpose of this study was to determine the impact of using tote bag on knowledge and attitudes of Posbindu cadres in measuring anthropometry and balanced nutrition in the elderly. The research design used the Quasi Experiment method with one group pre-test and post-test design on 35 Posbindu cadrerrespondents in the Pondok Kacang Timur area, Pondok Aren, South Tangerang. Measuring knowledge and attitudes using a pre-post test questionnaire. The bivariate analysis used is the Paired Sample T-test for data that is normally distributed and the Wilcoxon test for data in not normally distributes. The results show that there is a change in the mean value of knowledge and attitudes of Posbindu cadres in measuring anthropometry and balanced nutrition in the elderly compared to before and after the intervention. Education using tote bag can change the knowledge and attitudes of Posbindu cadres in measuring anthropometry and balanced nutrition in the elderly.
\end{abstract}

Keywords: Antrhropometry, Balanced Nutrition for the Elderly, Posbindu Cadres

\title{
I. PENDAHULUAN
}

Posbindu diperuntukkan bagi masyarakat lansia diwilayah tertentu, terdapat pelayanan kesehatan serta kegiatan untuk meningkatkan kesehatan yang melibatkan peran masyarakat dan organisasi sosial. Posbindu terdiri dari beberapa kader yang bersedia menyelenggarakan kegiatan posbindu secara sukarela (Erpandi, 2014). Kader mempunyai peranan yang penting karena mereka adalah pelayanan kesehatan (health provider) yang ada didekat kegiatan serta frekuensi tatap muka kader lebih sering dari petugas kesehatan yang lain (Wahyutomo, 2010). Agar kualitas pelayanan kesehatan meningkat kader harus memiliki keterampilan. Beberapa keterampilan kader ialah mengukur tinggi badan dan berat badan lansia (M Fitri \& Mardiana, 2011). Penilaian antropometri dengan parameter tinggi badan dan berat badan sangat penting pada saat menilai status gizi karena data antropometri di Indonesia masih terbatas. Tugas kader posbindu adalah mengukur antropometri pada lansia agar mengetahui status gizi lansia tersebut. Pengukuran antropometri harus dilakukan dengan tepat, parameter antropometri yang dipakai oleh kelompok lansia ialah dengan mengukur tinggi badan (TB) serta berat badan (BB) yang dituangkan dalam Indeks Massa Tubuh (IMT). Tetapi mengukur tinggi badan sukar dilakukan hal ini disebabkan oleh postur tubuh lansia yang mengalami perubahan akibat penuaan. Tetapi ada cara lain untuk mengatasi hal tersebut dengan menggunakan prediksi tinggi lutut, panjang depa beserta tinggi duduk untuk memperoleh tinggi badan prediksi lansia sedangkan untuk berat badan lansia yang tidak mampu berdiri bisa menggunakan prediktor lingkar lengan atas oleh karena itu kader harus bisa mengukur antropometri lansia dengan tepat pada saat lansia berkunjung ke posbindu. 
Pengetahuan bisa didapat melalui berbagai cara, misalnya ikut dalam pelatihan, penyuluhan, serta membaca (Kartini et al., 2019). Pengetahuan selalu berkaitan dengan proses belajar. Kader memiliki peran seperti pelaku dari sistem kesehatan, kader diharapkan dapat memberikan beberapa pelayanan yang mencakup pengukuran tinggi dan berat badan, mengisi lembar KMS dan mengajak lansia untuk hadir dalam kegiatan posyandu lansia (Kemenkes, 2010). Kader sangat diperlukan untuk menunjang kesehatan lansia. Jika kemampuan kader rendah dapat berpengaruh pada kualitas kesehatan lansia dan gizi kelompok usia lanjut diwilayahnya. Kader harus diberikan pengetahuan tentang pengukuran antropometri agar dapat mengukur dengan tepat supaya data yang didapat benar, kemudian kader juga harus diberikan pengetahuan mengenai gizi seimbang pada lansia untuk membekali diri mereka dalam menjawab permasalahan gizi yang ada di masyarakat. Menurut (Rahmawati, 2016) pengetahuan kader sangat penting untuk pedoman utama bagi kader selama melakukan perannya dalam memberikan pelayanan kesehatan yang baik. Salah satu pelayanan kesehatan adalah dapat melakukan pengukuran antropometri dengan tepat. Mengukur antropometri dengan parameter TB dan BB penting untuk menilai status gizi lansia, tetapi mengukur tinggi badan lansia sulit dilakukan karena lansia mengalami perubahan postur tubuh akibat penuaan (osteoporosis, kifosis, atau harus duduk dikursi roda) (Fatmah \& Nasution, 2012). Oleh karena itu peneliti ingin memberikan edukasi mengenai pengukuran antropometri dan pengetahuan gizi seimbang pada lansia kepada kader posbindu, karena permasalahan tersebut dapat diatasi dengan menggunakan prediktor tinggi lutut, panjang depa serta tinggi duduk untuk memperoleh TB lansia sedangkan BB bisa memakai prediktor lingkar lengan atas agar memperoleh BB prediksi lansia. Dalam penyampaian informasi penelitian ini menggunakan alat bantu media edukasi yang berupa tote bag. Media dibutuhkan sebagai perantara antara penyuluh dan peserta didik, media dibuat agar pengetahuan yang ada pada setiap orang dapat diterima atau ditangkap melalui panca indera. Tujuan peneliti untuk mengetahui pengaruh pemberian media tote bag terhadap perubahan pengetahuan dan sikap kader posbindu dalam pengukuran antropometri dan gizi seimbang pada lansia. Indikator keberhasilan diukur dengan nilai pre-test dan post-test.

\section{METODE}

Penelitian ini menggunakan quasi eksperimen dengan rancangan One Group Pre-test Post-test Design. Pelaksanaan penelitian di Posbindu Teratai, Posbindu Dahlia dan Posbindu Bougenvil yang berada dilingkungan Pondok Kacang Timur, Pondok Aren, Kota Tangerang Selatan. Pada tanggal 20 Juli 2020 sampai dengan 10 Agustus 2020.

Sebelum dilakukan intervensi kader harus mengisi kuesioner pre-test terlebih dahulu, setelah itu peneliti memberikan intervensi menggunakan media tote bag. Selang 1 minggu 
setelah diberikan intervensi, peneliti kembali untuk meminta kader mengisi kuesioner post-test untuk mengetahui apakah ada pengaruh dari pemberian media tote bag dalam perubahan pengetahuan serta sikap kader posbindu.

Populasi dalam penelitian ini adalah seluruh kader posbindu Pondok Kacang Timur, Pondok Aren, Tangerang Selatan yang berjumlah 63 orang, kemudian disederhanakan menggunakan software GPower versi 3.1. dan didapatkan jumlah responden yang dibutuhkan sebanyak 47 orang. Sampel penelitian ini sebanyak 35 orang berdasarkan kriteria inklusi dan ekslusi.

Pengumpulan data indentitas responden, pengetahuan dan sikap tentang pengukuran antropometri, pengetahuan serta sikap mengenai gizi seimbang pada lansia menggunakan kuesioner yang telah di uji validitas dan realibilitas. Data diolah dengan aplikasi SPSS. Analisis data dilakukan dengan dua cara yaitu analisis univariat untuk mendeskripsikan karakteristik setiap variabel yang telah diteliti. Kemudian analisis bivariat, untuk data pengetahuan pengukuran antropometri pada lansia dan pengetahuan tentang gizi seimbang pada lansia menggunakan uji statistik Paired Sample t-Test karena data berdistribusi dengan normal. Lalu untuk data sikap pengukuran antropometri pada lansia dan sikap gizi seimbang pada lansia menggunakan uji Wilcoxon karena data berdistribusi tidak normal dengan tingkat kepercayaan $95 \%(\mathrm{p} \leq 0,05)$.

\section{HASIL}

Sampel pada penelitian ini adalah kader posbindu yang berlokasi di Pondok Kacang Timur sebanyak 35 kader. Dari 35 kader sebagian besar berusia 45-59 tahun yaitu sebanyak 32 orang $(91,4 \%)$. Seluruh kader posbindu berjenis kelamin perempuan dan sebagian besar sudah lama bekerja menjadi kader 2-5 tahun sebanyak 21 orang $(60,0 \%)$. Terlebih lagi ada yang sudah menjadi kader selama lebih dari 10 tahun $(22,9 \%)$ (Tabel 1).

Tabel. 1 Karakteristik responden

\begin{tabular}{lcc}
\hline \multicolumn{1}{c}{ Karakteristik } & Jumlah & \\
\cline { 2 - 3 } Umur (tahun) & $\mathbf{n}$ & \% \\
45-59 & 32 & 91,4 \\
$60-74$ & 3 & 8,6 \\
\hline Jenis Kelamin & & \\
Perempuan & 35 & 100 \\
\hline Lama Menjadi Kader & & \\
2-5 tahun & 21 & 60,0 \\
6-9 tahun & 6 & 17,1 \\
$>10$ tahun & 8 & 22,9 \\
\hline
\end{tabular}


Nilai rata-rata pengetahuan kader tentang pengukuran antropometri mengalami peningkatan pada saat pre-test dan post-test untuk nilai pre-testnya yaitu 53,54 dan nilai posttestnya ialah 67,20. Sikap kader dalam pengukuran antropometri pada lansia nilai rerata mengalami peningkatan yaitu pada saat pre-test 67,80 dan nilai post-testnya 79,11 . Berdasarkan perhitungan uji paired sample t-test pada pengetahuan pengukuran antropometri didapatkan nilai p-value sebesar 0,001 $(\mathrm{p} \leq 0,05)$ nilai tersebut menandakan bahwa pemberian media tote bag berpengaruh dalam peningkatan pengetahuan kader posbindu dalam pengukuran antropometri pada lansia dengan derajat kepercayaan 95\%. Untuk sikap pengukuran antropometri didapatkan nilai $\mathrm{p}$-value sebesar $0,001(\mathrm{p} \leq 0,05)$ dari hasil perhitungan uji wilcoxon yang menandakan bahwa ada pengaruh yang signifikan pada peningkatan nilai sikap kader posbindu dalam pengukuran antropometri pada lansia antara pre-test dan post-test dengan derajat kepercayaan $95 \%$.

Tabel. 2 Pengetahuan dan Sikap Pengukuran Antropometri Sebelum dan Sesudah Edukasi

\begin{tabular}{|c|c|c|c|c|}
\hline Pengukuran & opometri & Mean \pm SD & Selisih & P-Value \\
\hline \multirow[b]{2}{*}{ Pengetahuan } & Pre-test & $53,54 \pm 14,504$ & \multirow[b]{2}{*}{13,66} & \multirow[b]{2}{*}{0,001} \\
\hline & Post-test & $67,20 \pm 20,821$ & & \\
\hline \multirow[b]{2}{*}{ Sikap } & Pre-test & $67,80 \pm 9,576$ & \multirow[b]{2}{*}{11,31} & \multirow[b]{2}{*}{0,001} \\
\hline & Post-test & $79,11 \pm 11,135$ & & \\
\hline
\end{tabular}

Untuk rerata pengetahuan terhadap gizi seimbang nilai rata-ratanya mengalami peningkatan dari nilai pre-testnya 72,23 menjadi 83,57 pada post-test. Sedangkan nilai rerata sikap terhadap gizi seimbang pada saat pre-test 80,37 dan post-testnya sama yaitu 88,17. Pengetahuan terhadap gizi seimbang didapatkan dengan hasil perhitungan uji paired sample ttest dan diperoleh nilai $\mathrm{p}$-value sebesar $0,001(\mathrm{p} \leq 0,05)$ nilai tersebut menandakan bahwa pemberian media tote bag berpengaruh dalam peningkatan pengetahuan kader posbindu terhadap gizi seimbang pada lansia dengan derajat kepercayaan 95\%. Berdasarkan perhitungan uji wilcoxon pada sikap terhadap gizi seimbang diperoleh nilai $p$-value sebesar $0,004(p \leq 0,05)$ nilai tersebut menandakan bahwa ada pengaruh yang signifikan pada peningkatan nilai sikap kader posbindu terhadap gizi seimbang pada lansia antara pre-test dan post-test dengan derajat kepercayaan $95 \%$. 
Tabel. 3 Pengetahuan dan Sikap Gizi Seimbang Lansia Sebelum dan Sesudah Edukasi

\begin{tabular}{|c|c|c|c|c|}
\hline Gizi Seiml & Lansia & Mean \pm SD & Selisih & P-Value \\
\hline \multirow[b]{2}{*}{ Pengetahuan } & Pre-test & $72,23 \pm 14,225$ & \multirow[b]{2}{*}{11,34} & \multirow[b]{2}{*}{0,001} \\
\hline & Post-test & $83,57 \pm 10,435$ & & \\
\hline \multirow{2}{*}{ Sikap } & Pre-test & $80,37 \pm 16,358$ & \multirow{2}{*}{7,8} & \multirow[b]{2}{*}{0,004} \\
\hline & Post-test & $88,17 \pm 9,790$ & & \\
\hline
\end{tabular}

\section{PEMBAHASAN}

Menurut hasil penelitian yang sudah dilakukan pengetahuan kader mengenai pengukuran antropometri mengalami perubahan dari yang sebelumnya kader hanya mengetahui cara mengukur berat badan dengan menggunakan timbangan kini kader tahu bahwa lingkar lengan atas dapat dipakai sebagai pengukuran berat badan (Mulyasari \& Purbowati, 2018). Selain itu pengetahuan mengenai pengukuran tinggi badan lansia yang tidak mampu berdiri dapat menggunakan parameter tinggi lutut, panjang depa serta tinggi duduk untuk mengetahui tinggi badan lansia (Riski et al., 2018). Pengetahuan kader meningkat setelah mendapatkan edukasi menggunakan media tote bag, hal tersebut sejalan dengan penelitian yang dilakukan oleh Shrestha \& Angolkar (2014) yang menyatakan pengetahuan meningkat setelah diberikan edukasi gizi, hal ini terlihat dari perbedaan yang signifikan antara pengetahuan sebelum dan sesudah.

Pengukuran tinggi badan serta berat badan yang sudah diperoleh bisa digunakan untuk mengetahui status gizi lansia dengan perhitungan Indeks Massa Tubuh (IMT). Menurut (Sitoayu \& Sudiarti, 2012) penentuan status gizi dilakukan dengan menggunakan pengukuran yang tepat, yang bisa menggambarkan keadaan gizi sebenarnya. Alat ukut yang bisa menjadi salah satu faktor kesalahan dalam menentukan status gizi, biasanya IMT selalu digunakan untuk menentukan status gizi karena sederhana dan murah untuk digunakan.

Menurut (Suharyat, 2009) sikap merupakan cara bereaksi terhadap suatu perangsang. Suatu kecenderungan untuk bereaksi terhadap suatu perangsang atau situasi yang dihadapi. Berdasarkan hasil analisa terdapat perbedaan sikap kader sebelum dan sesudah diberikan informasi tentang pengukuran antropometri pada lansia. Hal tersebut sejalan dengan penelitian (Sari et al., 2012) bahwa informasi yang didapat oleh seseorang bisa berpengaruh pada perubahan sikap yang membutuhkan bantuan agar terjadi proses dan pemahaman dalam diri seseorang. Media tote bag ini diberikan agar kader dapat membaca secara berulang informasi yang ada didalam tote bag sehingga kader semakin paham, karena salah satu fungsi media adalah untuk alat peraga dalam menyampaikan suatu informasi (Bertalina, 2016). 
Ketidaktahuan lansia akan kebutuhan gizi dalam pemilihan jenis makanan yang sesuai dengan kebutuhannya merupakan faktor yang menunjang seorang lansia mengalami kekurangan gizi. Asupan gizi merupakan penyebab tingkat kesehatan lansia menurun. Apabila lansia mengonsumsi asupan gizi yang baik maka dapat meningkatkan tingkat kesehatannya. Jenis makanan kerap kali menjadi gangguan untuk lansia dalam mencukupi asupan gizi mereka karena fungsi sistem pencernaan lansia sudah mulai menurun (Anna et al., 2017). Tetapi saat ini lansia sudah bisa mendapatkan informasi mengenai gizi seimbang jika berkunjung ke posbindu karena kader sudah memiliki pengetahuan tentang gizi seimbang pada lansia, salah satunya adalah makanan yang jumlah konsumsinya perlu dibatasi oleh lansia. Nilai pengetahuan tentang gizi seimbang pada lansia mengalami peningkatan sebesar 11,34. Pengetahuan tentang gizi seimbang sebelum dan sesudah diberikan media tote bag mengalami perubahan.

Pada dasarnya, seseorang bertindak atau bersikap didorong oleh adanya suatu kebutuhan. Selain kebutuhan faktor yang berperan dalam terbentuknya sikap adalah motif dan dorongan, perangsang atau penguat dan pengaruh sikap serta kepercayaan (Supariasa, 2011). Nilai rata-rata sikap gizi seimbang mengalami peningkatan sebesar 7,8 hal ini dikarenakan kader sudah mendapatkan informasi sehingga paham dan dapat menerapkan dilingkungan keluarga ataupun masyarakat sekitar.

\section{KESIMPULAN}

Pengetahuan dan sikap kader posbindu tentang pengukuran antropometri dan gizi seimbang pada lansia sebelum diberikan edukasi menggunakan media tote bag berbeda dengan setelah diberikan edukasi menggunakan media tote bag. Pemberian edukasi dengan media tote bag dapat berpengaruh dalam perubahan pengetahuan serta sikap kader posbindu.

\section{DAFTAR PUSTAKA}

Anna, A. N., Chusniatun, C., \& Rudiyanto, R. (2017). Kegiatan Penyuluhan Gizi Lansia di Posyandu Aisyiah, Mawar Biru, dan Anggrek Berseri Kelurahan Serengan. URECOL, 103112.

Bertalina, B. (2016). Pengaruh Promosi Kesehatan terhadap Peningkatan Pengetahuan tentang Gizi Seimbang pada Siswa Sekolah Dasar Negeri di Kecamatan Rajabasa Kota Bandar Lampung. Jurnal Kesehatan, 6(1).

Erpandi. (2014). Posyandu Lansia; Mewujudkan Lansia Sehat, Mandiri, dan Produktif. EGC.

Fatmah, F., \& Nasution, Y. (2012). Peningkatan Pengetahuan dan Keterampilan Kader Posbindu dalam Pengukuran Tinggi Badan Prediksi Lansia, Penyuluhan Gizi Seimbang dan 
Hipertensi Studi di Kecamatan Grogol Petamburan, Jakarta Barat. Media Medika Indonesiana, 46(1), 61-68.

Kartini, T. D., Manjilala, M., \& Yuniawati, S. E. (2019). Pengaruh Penyuluhan terhadap Pengetahuan dan Praktik Gizi Seimbang pada Anak Sekolah Dasar. Media Gizi Pangan, 26(2), 201-208.

Kemenkes, R. (2010). Pedoman Pembinaan Kesehatan Lanjut Usia Bagi Petugas Kesehatan. Direktorat Bina Kesehatan Komunitas.

M Fitri, H., \& Mardiana. (2011). Keterampilan Kader Posyandu Sebelum dan Sesudah Pelatihan. Jurnal Kesehatan Masyarakat, 7(1), 25-31. http://journal.unnes.ac.id/index.php/kemas

Mulyasari, I., \& Purbowati, P. (2018). Lingkar Lengan Atas dan Panjang Ulna Sebagai Parameter Antropometri untuk Memperkirakan Berat Badan dan Tinggi Badan Orang Dewasa. Jurnal Gizi Indonesia (The Indonesian Journal of Nutrition), 7(1), 30-36.

Rahmawati, E. (2016). Pengaruh Pelatihan Care for Child Development Terhadap Pengetahuan dan Sikap Kader Posyandu di Kota Yogyakarta. Repository Universitas Gajahmada.

Riski, F., Kartasurya, M. I., \& Pradigdo, S. F. (2018). Penggunaan Tinggi Lutut dan Panjang Depa Sebagai Prediktor Tinggi Badan dan Indeks Massa Tubuh pada Lansia di Kelurahan Sambiroto Kota Semarang. Jurnal Kesehatan Masyarakat (e-Journal), 6(5), 378-387.

Sari, E. K., Ulfiana, E., \& Rachmawati, P. D. (2012). Pengaruh Pendidikan Kesehatan Gosok Gigi dengan Metode Permainan Simulasi Ular Tangga terhadap Perubahan Pengetahuan, Sikap, dan Aplikasi Tindakan Gosok Gigi Anak Usia Sekolah di SD Wilayah Paron Ngawi. Indonesian Journal of Community Health Nursing, 1(1).

Shrestha, A., \& Angolkar, M. (2014). Impact of Health Education on the Knowledge and Practice Regarding Personal Hygiene Among Primary School Children in Urban Area of Karnataka, India. IOSR Journal of Dental and Medical Sciences, 13(4), 86-89.

Sitoayu, L., \& Sudiarti, T. (2012). Studi Validasi Pengukuran Antropometri dan Model Prediksi Terhadap Persen Lemak Tubuh BIA pada Siswa MTS dan MA Multiteknik Yayasan Asih Putera Cimahi Tahun 2012. Forum Ilmiah, 13.

Suharyat, Y. (2009). Hubungan Antara Sikap, Minat dan Perilaku Manusia. Jurnal Region, 1(3), $1-19$.

Supariasa. (2011). Pendidikan dan Konsultasi Gizi. Buku Kedokteran EGC.

Wahyutomo, A. H. (2010). Hubungan Karakteristik dan Peran Kader Posyandu dengan Pemantauan Tumbuh Kembang Balita di Puskesmas Kalitidu-Bojonegoro. UNS (Sebelas Maret University). 